\title{
Constructionist Perspective of Organizational Data Mining
}

\author{
Isabel Ramos \\ Universidade do Minho, Portugal \\ João Álvaro Carvalho \\ Universidade do Minho, Portugal
}

\section{INTRODUCTION}

Scientific or organizational knowledge creation has been addressed from different perspectives along the history of science and, in particular, of social sciences. The process is guided by the set of values, beliefs and norms shared by the members of the community to which the creator of this knowledge belongs, that is, it is guided by the adopted paradigm (Lincoln \& Guba, 2000). The adopted paradigm determines how the nature of the studied reality is understood, the criteria that will be used to assess the validity of the created knowledge, and the construction and selection of methods, techniques and tools to structure and support the creation of knowledge. This set of ontological, epistemological, and methodological assumptions that characterize the paradigm one implicitly or explicitly uses to make sense of the surrounding reality is the cultural root of the intellectual enterprises. Those assumptions constrain the accomplishment of activities such as construction of theories, definition of inquiry strategies, interpretation of perceived phenomena, and dissemination of knowledge (Schwandt, 2000).

Traditionally, social realities such as organizations have been assumed to have an objective nature. Assuming this viewpoint, the knowledge we possess about things, processes, or events that occur regularly under definite circumstances, should be an adequate representation of them. Knowledge is the result of a meticulous, quantitative, and objective study of the phenomenon of interest. Its aim is to understand the phenomenon in order to be able to anticipate its occurrence and to control it.

Organizations can instead be understood as socially constructed realities. As such, they are subjective in nature since they do not exist apart from the organizational actors and other stakeholders. The stable patterns of action and interaction occurring internally and with the exterior of the organization are responsible for the impression of an objective existence.

\section{BACKGROUND}

\section{The Rational and Emotional Nature of Personal Knowledge}

Individual knowledge is actively constructed by the mind of the learner (Kafai \& Resnick, 1996).

We make ideas instead of simply getting them from an external source. Idea making happens more effectively when the learner is engaged in designing and constructing an external artifact, which is meaningful for the learner, and he or she can reflect upon it and share it with others. From this constructionist description of the learning process, we can emphasize several elements associated with the creation of knowledge, namely, cognition, introspection, action, interaction, and emotion.

Through cognitive processes, humans construct mental representations of external and mental objects. Introspection is a specific type of cognition that permits the personal inquiry into subjective mental phenomena such as sensory experiences, feelings, emotions, and mental images (Damásio, 1999; Wallace, 2000). Through action and interaction, we create our experiences of the world we live in. The effective construction of personal knowledge requires the building of relationships between concepts and other mental constructs, in profoundly meaningful experiences (Shaw, 1996). All human experience is mediated by emotions, which drive our attention and concentration in order to help us to process external stimuli and to communicate with others.

\section{The Historical and Socio-cultural Context of Knowledge}

A social reality is a construction in continuous reformulation that occurs whenever social actors develop social constructions that are external and sharable. 
By the mere fact that people interact, influencing each other's mental constructs, social reality is in constant reconstruction. In this context, learning of new concepts and practices are happening continuously, either intentionally or unintentionally.

Learning happens inside specific mental and social spaces, meaning that what a group can learn is influenced by:

- The concepts, schemata, values, beliefs, and other mental constructs shared by the group.

- All knowledge we create about external things, events, and relationships, is based on and constrained by our mental constructs.

- The creation of knowledge is founded on the historical and socio-cultural context of its creators, providing a shared basis for the interaction inside a group. The continuous interaction of the group members, happening in a common environment, leads to similar mental constructs, a common interpretation of events, and the creation of shared meaning structures and external constructions.

- There is no viewpoint outside human subjectivity or historical and socio-cultural circumstances from which to study phenomena and to judge the inquiry process and the knowledge produced.

\section{ODM AND KNOWLEDGE CREATION: PROBLEMS AND OPPORTUNITIES}

ODM (also called Organizational Knowledge Discovery) has been defined as the process of analyzing organizational data from different perspectives and summarizing it into useful information for organizational actors who will use that information to increase revenues, reduce costs, or achieve other relevant organizational goals and objectives (Fayyad, Piatetsky-Shapiro, \& Smyth, 1996; Matheus, Chan, \& Piatetsky-Shapiro, 1993).

Data mining is a sub-process of the knowledge discovery. It leads to the finding of models of consumer behavior that can be used to guide the action of organizational actors. The models are built upon the patterns found out among data stored in large databases that are backed by statistical correlations among that data. Those patterns are extracted by specific mechanisms called data mining algorithms.

Attached to the discourse around the data mining tools, there is the idea that in the future, new and more powerful algorithms will be developed that will be able to find more valuable patterns and models, independently from human subjectivities and limitations. If it ever becomes possible to integrate the knowledge of the relevant business domain into the system, the algorithm would be able to decide the usefulness and validity of discovered patterns, correlations and models as well as to grow in sophistication by integrating these models in its knowledge of the business. The decision-making process would become extensively automated and guided by the objective reasoning of clear and rational rules implemented in a computer-based system.

However, this view has several drawbacks, namely:

1. Since all human knowledge has a tacit and nonexpressible dimension, it will never be possible to integrate all relevant business knowledge in a repository to be analyzed by a data-mining algorithm.

2. The diversity of views about the business activities and their context is what allows for the emergence of organizational creativity and development and the challenge of taken-for-granted concepts and practices (Bolman \& Deal, 1991; Morgan, 1997; Palmer \& Hardy, 2000). The stored knowledge representations are those around which there is some degree of consensus. This is important for the stability of work concepts and practices and to support organizational cohesion. However, they may also trap organizational actors in those concepts and practices, even when evidence shows they are threatening organizational success.

3. The relevance of knowledge representations stored in organizational repositories changes according to changes in the socio-cultural circumstances that offer the context for making sense of the representations. Only the organizational actors can understand those contexts and are able to give meaning to knowledge representations.

4. It is still believed that decision-making is or should be an essentially rational process, guided by cognitive processes such as planning, resolution of problems, and creativity (Sparrow, 1998). However, recent experiments in neurobiology show that emotion is an integral part of reasoning and decisionmaking (Damásio, 1999). Thus, only organizational actors can make decisions. The full automation of the process is not a realistic objective.

Instead of the present focus on the technological side of ODM, it would be interesting to adopt a constructionist approach and to focus on the social process of knowledge construction that makes ODM meaningful. With this new focus on people and the way they create and share knowledge, the main concern would be to mobilize the knowledge of organizational actors so the whole organization can benefit from it. This concern is justified by the awareness that the organization, seen as a community, is more intelligent than each one of its members, including any of its leaders. 


\section{LEVERAGING KNOWLEDGE CREATION IN ORGANIZATIONS: SOME CONSTRUCTIONIST GUIDELINES FOR ODM}

With ODM, there is a special focus on knowledge about consumer behavior to support decision and action. ODM assists the organization in knowing the preferences of its customers and in anticipating their needs and reactions. The construction of this knowledge must be guided by the specific purposes of the several communities of practice that constitute the organization.

ODM and the knowledge it helps to create are social constructions. Repositories, data mining tools, and the resulting patterns, correlations and models are social artifacts that should be used to make ideas tangible, to negotiate meanings, and to facilitate communication between organizational actors. As such, they may become catalysts for the development of shared knowledge about consumer behavior, when they are used in the contexts of meaningful projects.

Data mining systems may become empowering tools in the sense that they make viable the analysis of large organizational repositories of knowledge representations. These knowledge representations are social constructions that connect organizational actors to a common view of the business concepts and practices that shape their intentions and interactions. Problems in the performance of organizational tasks or in organizational adaptation to environmental changes may reside in the inappropriateness of knowledge representations or in the tools used to extract rules and patterns from them. Knowledge representations were created and stored under specific historical and socio-cultural circumstances of which their readers must be aware in order to be able to understand their relevance or inadequacy.

Table 1 summarizes the constructionist guidelines for ODM, grouping them in two categories:

- guidelines that should be considered for the creation of rich learning environments in which data mining systems are used as social artifacts that leverage continuous learning, and

- $\quad$ guidelines that should be considered when using a specific data mining tool.

These guidelines are given from constructionist theories developed and applied in areas such as psychology, education, and organization theory.

\section{FUTURE TRENDS}

According to the assumptions of the constructionist perspective, ODM should be designed to involve organizational actors in the social construction of something

Table 1. A summary of constructionist guidelines for ODM

\section{Creating rich learning environments}

Work relationships must be strengthened in order to create the social cohesiveness needed for the ongoing production of shared constructions that engage the organization in developmental cycles.

The construction of knowledge about customers' preferences and their future needs and reactions must be guided by the shared purposes of the specific communities of practice that constitute the organization.

Organizational repositories, data mining tools, and the results of data mining are social artifacts that should be used to make ideas tangible, to negotiate meanings, and to facilitate communication between organizational actors.

Knowledge representations were created and stored under specific historical and sociocultural circumstances of which their readers must be aware in order to be able to understand relevance or inadequacy of those representations.

\section{Using data mining tools}

Data mining results will support insight and creativity when organizational actors have enough time to reflect upon them and the opportunity to externalize and discuss their interpretations.

Effective formal and informal communication must be fostered in order to become possible to discuss each other's interpretations of past experience in the light of the context in which it occurred.

Theoretical tools, locally or externally developed, should be used to critically analyze the old meaning structures, facilitating the rearrangement of those structures.

The search and interpretation of patterns and models of consumer behavior should be guided by a multi-dimensional knowledge of the business domain, and work concepts and practices. 
external and sharable. The designing of a marketing campaign, the making of a decision, the transformation of work concepts and practices are examples of social construction processes for which ODM could be viewed as relevant.

As a result of the process, the individual and shared knowledge will become more sophisticated, empowering the action of individuals and groups, and facilitating interaction. In this way, organizational actors consciously create cohesive and pluralist work environments, more prone to deal with problems and difficult decisions associated with consumer behavior. This perspective is more realistic than the traditional view of ODM as a process of making knowledge neutral and independent of the knower and social contexts in which it is created, in order to support decision-making processes idealized as inherently rational.

The tools used to support ODM fundamentally shape and define the process. Lack of appropriate tools impoverishes a social setting and makes social construction difficult. Future research is needed to study if current data mining systems facilitate organizational developmental activities. It will also be important to create practical experiences of designing and implementing the ODM process in specific organizational settings so that learning from a constructionist perspective can be supported.

\section{CONCLUSION}

This article describes ODM as a process for the social construction of knowledge. As such, the focus changes from the technology used to discover patterns in the stored data to the human and social issues surrounding knowledge creation in organizations.

Managers should provide the resources and the conditions for the emergence of rich learning environments in which data repositories and data mining tools sustain collective cognitive processes such as memory, reasoning, language and attention. In this way, ODM becomes a key organizational process in the construction of organizational representations of external realities. These representations will guide organizational decision and action. In accordance with this view, this article provides a summary of constructionist guidelines for ODM to help managers leveraging knowledge creation in organizations.

\section{REFERENCES}

Bolman, L.G., \& Deal, T.E. (1991). Reframing organizations: Artistry, choice, and leadership. San Francisco: Jossey-Bass Publishers.
Damásio, A. (1999). The feeling of what happens: Body and emotion in the making of consciousness. New York: Harcourt Brace.

Fayyad, U., Piatetsky-Shapiro, G., \& Smyth, P. (1996). From data mining to knowledge discovery: An overview. In U.M. Fayyad, G. Piatetsky-Shapiro, P. Smyth, \& R. Uthurusamy (Eds.), Advances in knowledge discovery and data mining (pp.1-34). Massachusetts: The MIT Press.

Kafai, Y., \& Resnick, M. (Eds.). (1996). Constructionism in practice: Designing, thinking, and learning in a digital world. Mahwah, NJ: Lawrence Erlbaum Associates.

Lincoln, Y.S., \& Guba, E.G. (2000). Paradigmatic controversies, contradictions, and emerging confluences. In N.K. Denzin \& Y.S. Lincoln (Eds.), Handbook of qualitative research (pp.163-188). Sage Publications.

Matheus, C.J., Chan, P.K., \& Piatetsky-Shapiro, G. (1993). Systems for knowledge discovery in databases. IEEE Transactions on Knowledge and Data Engineering, 5(6), 903-913.

Morgan, G. (1997). Images of organization. SAGE Publications.

Palmer, I., \& Hardy, C. (2000). Thinking about management, SAGE Publications.

Schwandt, T.A. (2000). Three epistemological stances for qualitative inquiry: Interpretivism, hermeneutics, and social constructionism. In N.K. Denzin \& Y.S. Lincoln (Eds.), Handbook of qualitative research (pp.189-213). Sage Publications.

Wallace, B. A. (2000). The Taboo of Subjectivity: toward a new science of consciousness. New York: Oxford University Press.

xShaw, A. (1996). Social constructionism and the inner city: Designing environments for social development and urban renewal. In Y. Kafai \& M. Resnick (Eds.), Constructionism in practice (pp.175-206). Lawrence Erlbaum Associates Publishers.

xSparrow, J. (1998). Knowledge in organizations: Access thinking at work. London: Sage Publications.

\section{KEY TERMS}

Constructionism: A set of theories that defines the human beings as active constructors of their own learning and development. This learning and development of 
knowledge happens more effectively when individuals are involved in the construction of something external, something that can be shared, or both.

Objective Social Reality: It has an independent existence from any account of it.

Objectivism: A set of theories that views true knowledge about external realities, and the process of its creation, as neutral and independent of the knowledge creator.

Rich Learning Environment: Learning environments in which the learner is empowered to create a strong connection with the reality of interest by directly experiencing with it in order to develop mental constructs that are deep, complex, pluralist, and emotionally rich.
Social Constructions: External and sharable concepts, associations, artifacts, and practices that people actively develop and maintain in their social settings. An organization is an example of a social construction that interconnects its members in a specific social setting, in which many other social constructions are continuously being developed and maintained.

Socially Constructed Reality: It is created through purposeful human action and interaction. This reality is shaped by the individual's subjective conceptual structures of meaning. It is reconstructed by the human interactions that support continuous reinterpretations and change of meanings. The social institutions are the means through which meanings are stabilized and the social reality assumes an objective appearance. 